\title{
Should End User Computing be in the Computing Curriculum?
}

\author{
Theresa McLennan, Clare Churcher and Sue Clemes
}

\author{
Centre for Computing and Biometrics \\ Lincoln University \\ Canterbury \\ New Zealand \\ \{mclennan, churchec\} Qlincoln.ac.nz
}

\begin{abstract}
Increasingly end users in organisations are having to become more responsible for their own computing. Many of their applications are developed using standard business packages, especially spreadsheets and database managers, rather than being produced as customised software by the company's IS team. While most university computing courses still devote considerable resources to teaching aspects of software development in the traditional style (analysis, design, programming, software engineering, HCI), few teach these same concepts in the context of application software, apart from the universal "introductory computing" paper. For the last six years Lincoln University has offered advanced papers in end user computing. A recent survey was undertaken to assess the usefulness of these papers for graduates in the workforce and to obtain suggestions for the way the curriculum should evolve. The survey revealed that our graduates consider these university subjects to have been among the most beneficial for coping with the workplace. Surprisingly, this perception was true both for graduates who classed themselves as "computer professionals" and also for those who used computers in another career.
\end{abstract}

\section{Introduction}

When you think of university computer science courses you think of programming, algorithms and network theory, but not application software. Studying application software, spreadsheets, database managers and so on, is generally not thought of as a worthy academic pursuit. It may be justifiable to include a little in a first year general computing course but apart from that it is a topic best left to evening classes at the local high school. Why is it academically sound to learn and practise the correct and efficient use of a compiler but regarded as somehow not quite correct to learn maintainable and efficient use of spreadsheets, database managers and other end user software at university level?

More and more users are now being required to construct their own solutions to computing problems using application software, rather than using custom software that has been developed for them in a traditional programming language. This is the concept of end user computing and has been well discussed in the literature (Panko, 1987 [1], Delligatta, 1992 [2], Halloran, 1993 [3] and many others). As application software becomes more powerful and complex the range of problems accessible in this way grows. Unfortunately, it cannot be assumed that the competence of the user is improving to match.

Spreadsheets, for example, are probably used in almost all computerised organisations (for a New Zealand study see Coy and Buchanan, 1997 [4]). The problems encountered in constructing a complex spreadsheet are just as perplexing as those found during traditional programming, and some of the pitfalls and subtleties are arguably more difficult to come to terms with. The error rates in spreadsheets are frightening (Panko, Website [5]) especially when you consider how many corporate, political and economic decisions are made using results obtained from them. 
Designing a good spreadsheet or database requires analysis skills, problem solving skills, knowledge of programming structures, scoping, awareness of maintainability and security issues, usability factors and reliable testing procedures. In fact it requires all the skills of any competent programmer but with an appreciation of the additional peculiarities and possibilities inherent in spreadsheet and database packages. Then there are the issues of deciding which types of software are best suited to particular jobs, moving data between them (e.g. from database to spreadsheet to statistical package and back), putting it all together with a scripting language and a well designed user interface, and finally creating word processed reports with live links to the data. Often this work is entrusted to someone who is self taught or has a few hours experience in a first year laboratory or night class.

A survey of members of the New Zealand Computer Society undertaken in 1995 (Monin [6]) asked respondents about the knowledge, skills and abilities required in IS positions. The largest group of respondents were consultants. Not surprisingly people and communication skills were ranked highest, followed by being able to keep abreast with new technology, information gathering techniques, personal computer systems and the use and evaluation of software packages. All of these can be classed as end user computing skills and certainly are all represented in the end user curriculum at Lincoln University. By comparison, programming (both in 3GLs and 4GLs) was placed towards the end of the list of valued skills. This difference between typical computer science curricula and the skills required in industry has also been addressed in Trauth, Farwell and Lee, 1993 [7].

Recent revisions of information systems curricula are reviewed in Caouette and Lutz, 1996 [8]. In 1995 the ACM, DPMA and Association for Information Systems (AIS) developed a joint curriculum and the Office Systems Research Association independently produced the "Organisational and End-user Information Systems Curriculum Model". Both these curricula recognise the vastly increased importance of end user computing in organisations. The latter has a module entitled "End-user Technology Solutions" [9]. However, this is deliberately presented as a framework, with little detail included.

In recognition of the increased importance and complexity of application software in both the business and scientific arenas, Lincoln University has introduced papers in end user computing at an advanced level. Following on from the fairly typical first year introductory computing paper there is a 200 level paper "Problem Solving on Microcomputers" and a 300 level paper "Advanced End User Computing”. These papers are available to both computing and non computing majors and have proven to be very popular. In 1997 a further paper "Multimedia Development and Application" has been added.

The aim of these papers is to produce graduates who can take unfamiliar problems, evaluate the software choices that are available at the time and produce accurate, maintainable and usable solutions.

To assess the usefulness of the end user papers for graduates in the workforce and to obtain suggestions for the way the curriculum should evolve, a survey of past students of the "Advanced End User Computing" (COMP307) paper was undertaken. The survey explored their employment history and general computing background. Its purpose was to discover the nature and scope of the computing activities in their employment and to try and determine the usefulness of the end user papers in equipping them with skills that were adaptable in a rapidly changing environment. Given the difficulties in locating long lost graduates the survey achieved an excellent return rate of $44 \%$ of those approached. The conclusions were overwhelmingly positive. $68 \%$ of the respondents rated the paper as being "one of the most useful" they had taken. Surprisingly, computing majors, now employed as computer professionals, regarded the end user paper as being one of the most useful they had taken, even though they would typically have taken many other more traditional computing papers in their courses.

The rest of this paper is constructed as follows. In section 2 we describe the content and rationale for the end user computing courses at Lincoln. In section 3 we present the survey methods and in sections 4 and 5 we discuss the most interesting results. 


\section{End User Computing at Lincoln}

Undergraduate computing students at Lincoln University fall into three broad categories. Those taking the Bachelor of Applied Computing (approximately half computing papers and half subjects from some other discipline), students taking the Bachelor of Commerce and Management degree (majoring in applied computing) and those wishing to include some computing as part of any of the degrees offered at Lincoln.

The emphasis of the end user computing papers at Lincoln is on problem solving and transferability of skills. The latter is extremely important as any product dependent skills will quickly become useless with the rapid evolution of software in today's market. The end user computing papers are in addition to the papers that are normally found in a computer science curriculum (programming, database theory, systems analysis, and technical computing papers) and are designed to be accessible to non computing majors as well as those specialising in computing.

A 200 level paper "Problem Solving on a Micro computer" was introduced in 1990. It tackles the dual problem of producing users competent and confident in the current batch of products and also aims to provide skills that will enable graduates to adjust to future developments - whatever they may be. The emphasis is on the individual solving real world problems rather than on doing short class exercises. This means tackling problems involved with transferring data between applications and dealing with all the complexity that a real situation introduces. Issues such as designing appropriate solutions, user interface design, documenting, testing and auditing are also covered and included in practical assignments.

A 300 level paper "Advanced End User Computing" was first taught in 1992 and builds on the skills acquired in the 200 level paper. Students continue to develop applications using a variety of packages and are expected to be able to transfer their skills to unfamiliar products of the same genre. Considerable emphasis is placed on designing applications that are accessible to other users. End user issues are also looked at from a management or project leader viewpoint. Topics include evaluating software and making decisions on the most appropriate type of software to use. As many of the graduates are expected to end up in positions of responsibility in a variety of organisations, issues such as how to introduce and manage end user computing in an organisation are addressed. Other topics such as security and privacy issues, user responsibility, and OOS are also introduced.

The papers have been extremely popular. Nearly all computing majors take them, and they are also attractive to non computing majors. Over the last five years $60 \%-70 \%$ of the 300 level class have majored in a subject other than computing, typically accounting, finance, general commerce or resource studies. For many of these students the end user paper may be the only advanced computing subject in their course. This year the end user papers have been included in the science schedule; a move that reflects their general utility.

\section{The Survey}

To assess the usefulness of the end user computing papers at Lincoln a survey was carried out in late 1996. The potential population numbered 199 and was made up of all students who had passed COMP307 during the years 1992 to 1995 and who were no longer at Lincoln University. Addresses were sought from the Lincoln University Alumni and were found for 160 people. We were aware, however, that many would be out of date. Responses were received from 70 people, $44 \%$ of those surveyed. $12 \%$ of the surveys were returned to sender and there were probably many more that never reached the intended recipients. Replies were received from New Zealand, Australia, England, Malaysia and Singapore. All other considerations apart the survey was a delightful way of catching up with news of our ex students. (It was engaging to find that someone we had taught had created the Eastenders' historical database at the BBC)

The survey results were generally representative of the population (Table 1). However, those with higher grades were somewhat over represented.

The full questionnaire is contained in McLennan, Churcher and Clemes, 1997 [10]. In summary it consisted of 3 sections. The first covered respondents' employment histories, the types of tasks that the computing component of their job involved and in particular asked if they described themselves as computer professionals. To help in their assessment they were advised that "An accountant is not a computer professional but a computer trainer is." 
The second section covered general computing background and perceived competence in computing.

The third section was more specific to COMP307. It assessed the respondents reasons for enrolling, their expectations and how they were met and the other computing subjects they had enrolled in. On a scale of 1-5 they were asked to rate its difficulty and its usefulness compared with the other subjects they had studied.

The final question in this section listed a number of topics for inclusion in COMP307 (Table 3), and on a Likert scale of $0-5$ asked the respondents to indicate those topics that were useful in their current jobs, and those they considered important to include in the COMP307 curriculum.

All the questions in the survey included room for comments.

\section{Results}

The full questionnaire and results can be found in McLennan et al, 1997 [10]. We include here a summary of those results that we found most interesting and relevant to curriculum issues.

The overwhelming opinion of the respondents was that the skills developed in their end user computing class were valuable.

- $\quad 86 \%$ used the skills in their present job

- $\quad 59 \%$ felt it gave them an advantage in applying for jobs

- $\quad 17 \%$ rated it the most useful paper they took at Lincoln while another $51 \%$ rated it more useful than most

A sample comment was:

"COMP307 gave me a definite advantage in obtaining my present job, especially the spreadsheets."

It was informative to break down the results into those who regarded themselves as currently working as either computer professionals or in some other role. It was interesting to note that some graduates who regarded themselves as computing professionals were not computer majors and so the end user papers were very probably the only formal computing they had taken in their degree. The proportions of the respondents in these groups are shown in Table 2. Note that the computer majors could have graduated as either a Bachelor of Applied Computing or as a Bachelor of Commerce and Management, majoring in applied computing. The group of seven who were computer majors but are not working primarily in computing, had probably completed a double major, such as accounting and computing.

\subsection{Usefulness of EUC Paper}

The response of the two groups on the usefulness of the end user computing paper was somewhat surprising.

- $91 \%$ of professionals and $83 \%$ of non professionals used end user computing skills in their current jobs

- $55 \%$ of professionals and $75 \%$ of non professionals thought the end user paper "a lot more useful than most" or "the most useful" paper that they took at university.

We were surprised at the large percentages in both groups who are using end user skills in their current employment especially those who regarded themselves as computing professionals. A considerable number of this group had taken many of the other traditional computing papers (programming, operating systems, algorithms etc) but still regarded the end user computing paper as "more useful than most".

Some comments from computing professionals were:

"It helped me view things from an end user's point of view when designing applications, forms, etc."

"I use the skills gained from this course daily."

\subsection{Important Topics}

The questionnaire also asked respondents to rate the usefulness of 24 end user topics in their current jobs with a Likert ranking of 0 (not applicable) to 5 (very useful). They were similarly asked to rank the importance they placed on including these topics in the curriculum, from 0 to 5 in increasing importance. The topics can be found in Table 3 and the results are summarised below in Figure 1.

It is interesting to note that apart from spreadsheet basics, moving data between applications was the most used skill. This reflects the changing environment in computing today. Much of the 
work is involved in moving data between existing applications rather than developing new applications. This might involve transferring partially processed data from one application package to another for further processing, or producing integrated reports with data from spreadsheets and databases linked to a word processed document. The respondents also clearly appreciated the need for being able to recognise the appropriate application to use in any given circumstance.

\begin{tabular}{|ll|}
\hline Spreadsheet basics : formulas, copying, & 4.3 \\
Moving data between applications & 4.0 \\
Selecting appropriate applications & 3.6 \\
E-mail & 3.5 \\
Spreadsheet databases & 3.2 \\
Spreadsheets using templates & 3.1 \\
Using tables in databases & 3.1 \\
Creating Database forms/reports & 3.0 \\
\hline Figure 1 Mean Responses for the Eight M ost Used \\
Topics
\end{tabular}

The least used skills from Table 3 (creating and using multi media applications, creating web pages and groupware), probably reflect the slow uptake of these new technologies among some employers. It would be interesting to revisit these questions again in a year or two.

The topics that the respondents identified as most important to teach were somewhat different. These are summarised in Figure 2.

\begin{tabular}{|lc|}
\hline Spreadsheet basics & 4.4 \\
Using multi-table databases & 4.3 \\
Creating database forms/reports & 4.3 \\
E-mail & 4.2 \\
Moving data between applications & 4.2 \\
Creating/modifying tables/databases & 4.2 \\
Selecting appropriate applications & 4.2 \\
Spreadsheet Databases & 4.0 \\
\hline Figure 2 M ean R esponses for the Eight Topics \\
Considered Most Important to Teach
\end{tabular}

Here "using multi-table databases", and other database topics were highly recommended although they were not "most used in the current job".

This possibly indicates that the respondents can see opportunities for using their database skills even though they may not be currently doing so. This could either be that their current environment does not allow them to use multi-table database, or that they feel less confident about doing so.
It is the opinion of the authors that because spreadsheet skills are somewhat more prevalent in the community than good database skills, that many individuals, companies and research institutions use spreadsheets in situations where a database would be more appropriate. Alternatively, data may be in a flat file database when it would be more effective in a relational database. The different results in "current use" versus "importance to teach" of database topics, supports both views and is a subject of ongoing research.

\section{Discussion}

The survey results confirmed our belief that advanced end user computing plays an important role in tertiary applied computing courses. The respondents mostly felt that the topics covered were valuable and applicable to real world problems. One criticism of this type of course can be that they constitute "training" in specific application software. The feedback we received demonstrates that the skills taught are genuinely transferable. Some respondents were using the skills more than four years after completing the subject by which time the specific software would be quite different. Typical comments included:

"I was able to say that although I hadn't used all the computer packages expected for the job, I had gained the skills to approach problems in a more competent manner."

"I use Access a lot and even though it was not in the course I can still use database skills learnt in Paradox, etc."

The skills were used by respondents in a variety of jobs. Theywere as much, if not more, appreciated by those in professional computing jobs as those in other jobs where end user computing is most often expect to occur. This was a particularly rewarding finding.

While spreadsheet skills are the most commonly used, respondents saw a definite need for improved database proficiency. While formal database theory and design are covered in other subjects available to computing majors at Lincoln University, there is clearly a need for aspects of these topics to be made more readily accessible to non computing specialists. 
The survey results were encouraging in reinforcing our views that a broad ranging computing education is essential in producing graduates able to adapt to the rapidly changing environment they will find themselves in.

\section{References}

[1] Panko, R. R. "Directions and Issues in End User Computing." INFOR, vol 5, no. 3, 1987, pp 181-197.

[2] Delligatta, A. "Managing End User Computing: Empowering the User Community. A Guide for IS Managers." Information Systems Management, Summer 1992, pp 63-64.

[3] Halloran, J. P. "Redefining End-User Computing: Achieving World-Class End User Computing. Making IT Work and Using IT Effectively." Information Systems Management, Fall 1993, pp 7-12.

[4] Coy, D. and Buchan, J. "Spreadsheet Use: A 10Year Study". Chartered Accountants Journal, April 1997, pp 62-66.

[5] Panko, R. R. "The Spreadsheet Research Website" http://www.cba.hawaii.edu/panko/ssr/

[6] Monin, D. J. "In an Era of Strategic Information Systems What Skills Inventory is Needed for Computing Professionals in New Zealand - An Historic Approach." New Zealand Journal of Computing, 6 (1B), Aug 1995, pp 275-285.

[7] Trauth, E.M. , Farwell, D.W., and Lee, D. "The IS Expectation Gap: Industry Expectations versus Academic Preparation." MIS Quarterly September 1993 pp $293-307$

[8] Caouette, J. and Lutz, C. "The Status of Model Curricula Development: A Look at the Efforts of ACM, DPMA and OSRA". Office Systems Research Journal, Spring 1996, pp 30-37.

[9] O'Connor, B (Ed.). "Organisational and End_user Information Systems Model Curriculum”. Office Systems Research Association, 1996. Springfield MO (Website:http://pages.nyu.edu/ oconnorb/osra /model_curriculum)

[10] McLennan, T. J., Churcher, C. D., Clemes, S.K. "End User Computing at Lincoln University: An Observational Study of Former Students." Research Report No: 97/06, Centre for Computing and Biometrics, Lincoln University. 1997. 
Table 1 Representativeness Of Survey

\begin{tabular}{|l|ll|}
\hline & Survey & Population \\
\hline Females & $35 \%$ & $33 \%$ \\
Computing Majors & $34 \%$ & $30 \%-40 \%$ in any year \\
A grades & $50 \%$ & $30 \%$ \\
B & $36 \%$ & $47 \%$ \\
C & $14 \%$ & $23 \%$ \\
\hline
\end{tabular}

Table 2 Sur vey Res pondents $\mathrm{Br}$ oken Dow $\mathrm{n}$ by Employment Category and Degree Type.

\begin{tabular}{|l|lll|}
\hline & Computer major & $\begin{array}{l}\text { Non computer } \\
\text { major }\end{array}$ & Total \\
\hline Employed as Computer Professional & $17(24 \%)$ & $5(7 \%)$ & $22(31 \%)$ \\
Non Computer Professionals & $7(10 \%)$ & $41(59 \%)$ & $48(69 \%)$ \\
Total & $24(34 \%)$ & $46(66 \%)$ & $70(100 \%)$ \\
\hline
\end{tabular}

Table 3: Selected Topics for the COMP307 Curriculum

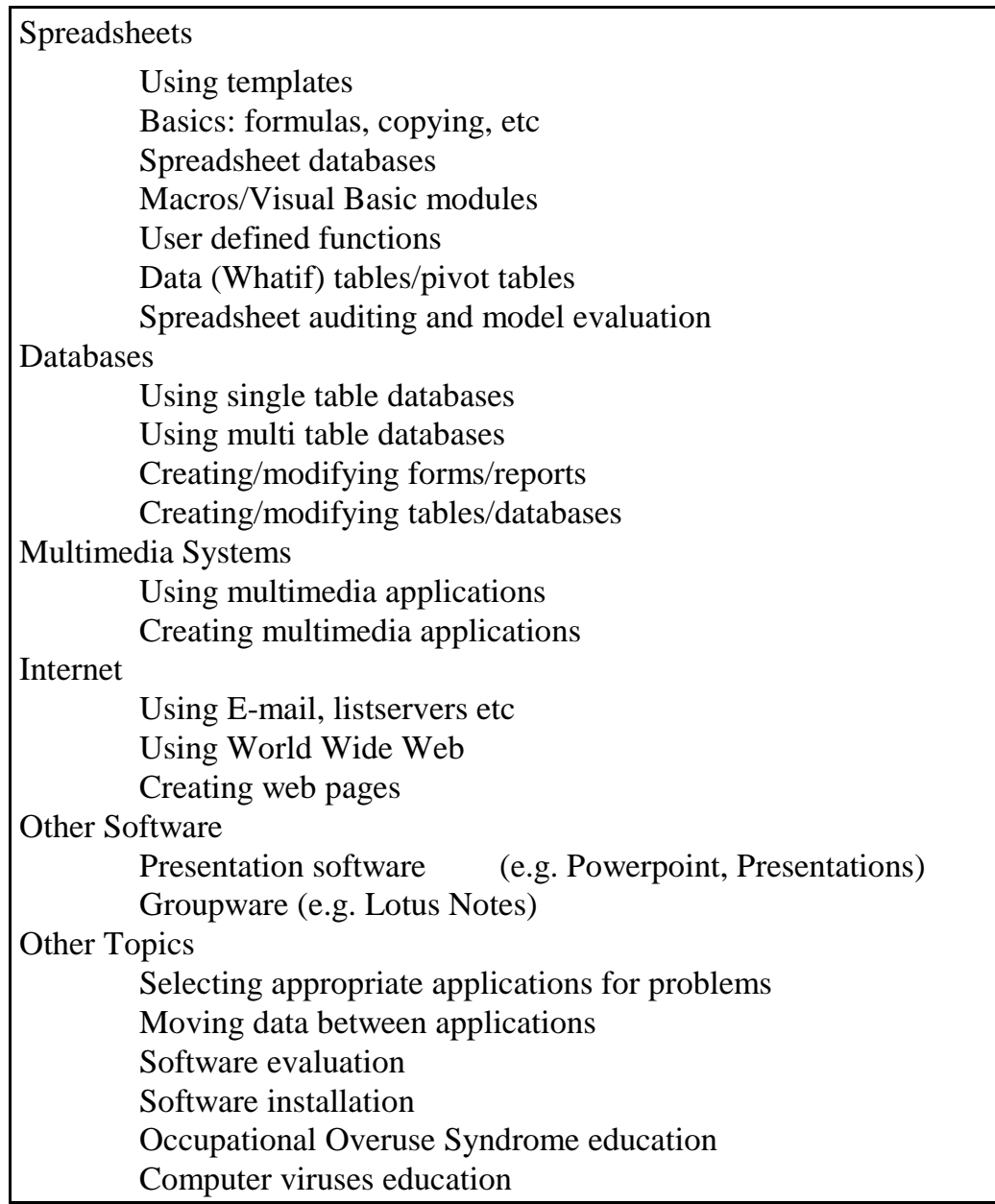

